\title{
REFLEXIVITY AND THE SYMBOLIC WE-RELATION
}

Lorenza Gattamorta

University of Bologna

Symbols tend, by their nature, to create bonds between different spheres of reality and show the intimate relationality between individuals and society: without others, individuals would not make use of symbols, and at the same time society depends on individuals' capabilities to know, think, and communicate through symbols in order to adapt, cast doubt on, or (attempt to) change society itself. Sociological analysis of symbolic processes has substantially developed along two lines of research: the first prevalently stresses that individuals are conditioned by symbolic processes, hence particular importance is given to the objective side of symbolization; the second line mainly emphasizes that individuals condition symbolic processes and particular importance is thus given to the subjective side of symbolization. The first line has been discussed in particular in the sociology of Durkheim and his successors; the second line has been developed especially in the phenomenological sociology of Schütz and his followers. Durkheim made a fundamental contribution to the study of social symbolism: starting from the premise that the glue of collective consciousness lies in the production and socialization of shared symbols, he came to the reductionist conclusion that there is an overlap between the symbolic and society. In Durkheim there is no lack of reference to the subjective side of symbolization, for instance, when he talks of the individual's integration in the collectivity through a process of symbolic identification. Nevertheless, in the general trend of his sociology, the scales definitely tend to dip towards the structural dimension of the symbolic. On the other hand, in his attempt to found a sociology upon the symbolic "We-relation," it can be observed that Schütz mainly looks at the symbol in an individualizing light. This essay will consider the features constituting the symbolic 
We-relation in order to try to discover how the reflexive Self (whose subjectivity emerges in the interaction with verbal and non-verbal symbols) can generate changes to the Self, the You, and the We-relation itself.

According to Schütz, ${ }^{1}$ the symbolic We-relation is formed through the attention we pay to the attitude of another person. In a relationship, individuals not only experience themselves and the other, but also the specific relationship itself. Hence, the experienced world is neither the private world of the Self nor the private world of the other, but the "We-world." While individuals can only grasp their thoughts as belonging to the past through reflection, within the limits in which they can experience the thoughts and acts of the other in the vivid present, they know more about the other and the other knows more about them than they each know about their own consciousness: this present, common to both, is the sphere of "We."

The We-relation not only provides the basis for intersubjectivity but the very "Thou-experience" itself (see Ivana 2016). In effect, it is true that in the natural attitude the Self can perceive changes in others' bodies as signs of their experiences of consciousness, that is, "the mere existence of a frame of reference referring to the other, of a system of interpretable signs or symbols, for instance, is sufficient for the belief in the existence of other persons" (Schütz 1942: 345). Nevertheless, the Thou-orientation is not sufficient to constitute the foundation of the Thou-experience because, in it, it is not possible to check that the observer's interpretation of the sense of the experiences matches the sense meant by the actor. In short, there is no sequence of reciprocal mirroring that allows real access to the modes of attention of the other's consciousness: "the mirroring of Self in the experience of the stranger (more exactly, in my grasp of the other's experience of me) is a constitutive element of the We-relation" (Schütz \& Luckmann 1975, Eng. transl. 1973: 67).

What has been illustrated thus far does not mean that for Schütz the We-relation equates to an explication of the nexus of subjective sense: the connection between behaviour and the meaning captured from it is in principle opaque, not explicit. To understand the connection between current behaviour and the meaning captured from it, it is necessary to reflect on past experience and exit the We-relation. The moment in which the Self reflects on the "We," the unity of the flow of experience dissolves,

\footnotetext{
1 In connection with the renewed centrality of social symbolism in Schützian studies, it must be remarked that the third conference of the International Alfred Schütz Circle for Phenomenology and Interpretive Social Science, held at Waseda University in Tokyo in 2016, was entitled "The Symbolic Construction of Reality".
} 
the Thou- and Self-experiences split, and Thou-meanings are no longer grasped as they are being produced but as products: the explication process consequently does not belong to the We-relation but presupposes it (see Schütz \& Luckmann 1975, Eng. transl. 1973: 63).

Schütz further investigates the symbolic characteristics of the We-relation in the essay Symbol, Reality and Society, which reads "[the Werelation] belongs to a finite province of meaning other than that of the reality of everyday life and can be grasped only by symbolization" (1972: 318). Schütz claims that in common-sense knowledge, the social world is experienced at two levels of appresentative references: that of individuals and that of social collectivities. Single individuals and their thoughts are grasped through signs, which are systems of appresentative references within the world of everyday life. According to Schütz, it is a matter of "immanent transcendence," namely, both members of the appresentative relationship through which this transcendence is grasped belong to the same province of meaning, the paramount reality. Social collectivities, however, not being entities that fall within the reality of everyday life but being constructs of common-sense whose reality lies in another sub-universe can only be grasped symbolically. For example, social collectivities or institutionalized social relations can be experienced by meeting individuals who appresent the government, such as a president or a minister. In this case, it is a "great transcendence." The appresentative element of this second appresentative relationship is the common situation as defined by the participants and the appresented idea is that of association, participation, and society: "the Werelation as such transcends the existence of either consociate within the paramount reality and can be appresented only by symbolization" (Schütz 1972: 353). The idea of partnership symbolizes the We-relation with different degrees of intimacy: We-colleagues, We-friends, We-lovers. In any case, "the symbols [appresenting social collectivities] pertain to the paramount reality and motivate our actions within" (ibid.). In social relations based on the We-relation, it is therefore not (only) pragmatic intention that motivates the action, but a symbolic element, transcending the reality of everyday life. In the end the "We" becomes the experience of Self and Thou as individuality and, at the same time, the constitution of a social relationship that should not be seen as the sum of Self and Thou, but in a certain sense as a new subject.

In its intrinsic tendency towards subjectivization (albeit collective, not of the single individual) the phenomenological approach to social relations may reveal some limits in a macrostructural type of analysis: for example, 
according to Donati (2011: 82), in Schütz's view of relations-which has been influenced by psychologism and the pragmatist philosopher William James, and has a certain tendency towards formalistic nominalism-it can be difficult to reconstruct relations from subjects taken individually, even when they are considered in terms of their intersubjective orientation. Donati distances himself from Schütz when Schütz puts the relational dynamic that comes before the subject in epoché-something that Schütz himself, albeit with some internal contradictions, criticized at a certain point of his career when he turned Husserl's concept of epoché into epoché of the natural attitude. It is precisely in this conception of a "We" that takes priority over the transcendentality of personal consciousness that Schütz's revision of Husserl's phenomenological method lies. And on this basis, it can be hypothesized that Donati might—at least partially—agree that the symbolic We-relation and the world of others (the Mitwelt) is not a secondary but an original phenomenon.

While it is evident that the subject's experience of his own action is theoretically different from the experiences of others' action with the same end, the reciprocity of perspectives allows Schütz to pass from a Self-centred to a socio-centred position and explains why it is possible that the sense of the world is shared even though the sense of individuals' experiences is radically subjective. In an essay on the sociology of music, Schütz further investigates the concept of this common "We" by pointing out that in his operas Mozart gives an exemplary representation of how human beings meet and communicate in a We-relation that does not correspond either to the sum of single individuals that make up the relationship or to an anonymous community that eliminates these same individuals' uniqueness: "In spite of their diversified reaction to the common situation, in spite of their diversified individual characteristics, they act together, feel together, will together as a community, as a We" (1956: 241).

Furthermore, Schütz (1951) in no way denies the fact that its conceptual structure and capacity to typicize make verbal language a preferred tool for transmitting meanings. Nevertheless, he considers that it is not linguisticverbal communication (which implies a semantic system) that necessarily underlies social relations. In certain cases (such as making music together), verbal communication can presuppose a prelinguistic underlying relationship, a non-conceptual "mutual tuning-in relationship." Donati's view is similar in certain respects. Despite starting from different epistemological presuppositions in regard to phenomenology, Donati also does not conceive of communication as a necessary foundation for the We-relation, but 
the We-relation as the foundation of communication. On the relationship between communication, culture and social relations, Donati's relational approach stands apart both from the structural-functionalist paradigm (for which communication is a product of culture) and the neo-functionalist constructivist paradigm (for which communication is a closed system that produces culture without any communicating subjects being seen): society is not made solely of communications, nor is it a communicating culture, but it is made from social relations that are communications between subjects who interact within a culture and through a culture. Thus, Donati seems more or less consciously to revive some of Schütz's intuitions- to the point of proposing a new sociological hermeneutics capable of grasping the processes conferring sense on the actual web of relations pertaining to our being in the world as subjects:

[the] social relation cannot be reduced to a symbolic mediation, a projection of individuals, or the expression of structures. It is something more and something different. Social relation is an invisible but real entity, which cannot be treated as a thing (as stated by the first rule of Durkheim's method) (Donati 2015: 87);

the We must be symbolized (by ego and alter avowing to being a couple in some way), even if the symbol employed is interpreted through different thoughts and meanings by ego and by alter. The symbol indicates the reality of the relation (We, not-Them), such that whatever the We does (for example, eating a meal together, spending a holiday together) is defined and lived as a relation (reciprocal action) (Archer \& Donati 2015: 185-186).

In order to try to overcome the difficulties of phenomenological and structuralist theories, those who deal with the sociology of symbolic processes and in particular with the symbolic We-relation should try to study the symbol by forming and maintaining a relationship between three elements: (a) reality, meant as the life-world, and as the world of the social construction and bond; (b) the symbolic, meant as the sphere of cultural production; (c) the knowing and acting subject. At this point, while making this attempt, in order to investigate the nature of symbolization it is necessary to discuss the Self's rationality in a perspective that seeks to avoid both a hypo-socialized and a hyper-socialized conception of that same Self. 
Social symbolization can be defined as a relationship that involves three terms: (a) a signifier (the symbol); (b) a signified (the symbolized) and (c) the subjects (individual and/or social) to whom the symbol refers, and for whom it replaces the symbolized (Gattamorta 2010: chap. 6). There is an intrinsic relationality between objects, signs, and interpretants. The very process of receiving and decoding systems cannot happen in a mechanical and passive way but through the (at least minimal) reflexivity of the interpretant subjects: "the symbol is thus more than a mere substitute stimulus - more than a mere stimulus for a conditioned response or reflex (...) the response to a symbol does and must involve consciousness" (Mead 1934: 125). ${ }^{2}$ It could also be said that "symbolic mediation" can be thought of as the "relational space between a reality in itself and the knowing subject (the latter immersed in the culture of collective symbolic representations, at the various levels of common-sense knowledge, institutional knowledge and macrosocial strategic knowledge)" (Donati 2002: 233). In addition, it can be observed that the symbol's raison d'être, its power, seems to come from social conditions and facts external to the symbol itself. ${ }^{3}$ Indeed, the symbol cannot be conceived in a merely subjective way (as an individual mental process that affects the objects), in the same way as it cannot be imprisoned in the social structure. Instead, it should be observed as an emerging dimension of social relations that presupposes a non-complete reduction of culture to the social. ${ }^{4}$ In this sense, one of sociology's primary objectives should be to "clarify the relationship between the intimate symbolic-relational constitution of the subject (in all I-Me relations) and the relational character of the context and the other variables (and levels) at play. The social relation is at the same time a container of symbolization and itself the producer of symbolization" (Donati 2009: 396).

On the one hand, a sociology of symbolic processes should share Jeffrey Alexander's (1987: 206) assumption (after Mead) that objects cannot

\footnotetext{
2 Also owing to this affirmation, Habermas deems that the symbol-led behaviour of which Mead speaks is an intentional action since "the meaning content of symbols is defined by the behavioural expectations and not by the modes of behaviour themselves. For this reason, the use of symbols cannot be reduced to mere behaviour" (1988: 65).

3 Bourdieu (1991: 109-115) proposes an evocative analogy between the power of the symbol and the power of the skêptron offered in Homer to the orator to take the podium. The latter does not receive authority from the skêptron itself but from the social role of orator, from the characteristics of the institution that legitimizes him to speak, and from the interlocutors who are listening (on the concept of symbolic politics, see Hałas 2002a).

4 The thesis which does not totally reduce the symbol to the social has a parallel—and it could not be otherwise seeing the affinity of the topics-in the rethinking of the relationship between the social and culture in the last two decades, with the affirmation of the so-called cultural turn in the human and social sciences (see Alexander \& Smith 2002).
} 
exist except for the context of social relations within which the symbolization takes place; on the other hand, it should place attention on not reducing objects to their mere symbolization in order not to repeat the errors made by Durkheim (whom Alexander himself defines as an idealist). The symbol is not merely subjective, nor is it, in itself, merely irrational even though it has unfortunately often become so in ideological systems. In the various forms of positivism, the symbolic tends to be confined to the sphere of the irrational. Sperber effectively summed up the positivist position on the symbol as follows: "the symbolic mechanism has as its input the defective output of the conceptual mechanism" (1975: 141). The line of argument commonly made to support the thesis of a gap between the conceptual and symbolic can also be described as follows:

since the individual feels a cognitive deficit in his experience of the world, namely he lacks suitable rational concepts to explain and understand the world (the others, etc.), he has to turn to something that motivates him to act. And so the rational-cognitive deficit is filled by symbolic experience which in reality is a sort of sublimation of an object of little value that is given a charismatic charge (Donati 2008: 99).

The asserted non-rationality of the symbol seems to have historically taken two fundamental directions. Those with links to an evolutionist cultural anthropology think that the symbolic is connatural to a primordial phase of humankind and can only have a marginal role in rationalized modern societies. On the other hand, more than a few people think that despite the historical constant joint presence of the symbolic and rationality the symbolic is confined to spheres of social life outside conceptual representations. Durkheim indirectly goes against the first of these two reductions when he shows that symbols are at the centre of the social and cultural life not only of tribal societies but also modern societies; Mauss fought against the second, attributing a fundamental role to symbols by placing the "total social fact" (meant as the interrelation between the biological, psychic, social and symbolic) at the centre of the sociological investigation. Mauss thus tried to shift away from the trend-present in the sociology of culture and inherited by philosophy_of thinking of the symbolic as a peculiar

\footnotetext{
5 On the fact that an over-rationalized conception of society tends to ignore important phenomena such as those belonging to the symbolic domain see also Hałas (2002b).
} 
form of knowledge that has to be made to fit or extrinsically relate to other forms of more codified knowledge.

The true wager for a sociology of symbolic processes is to recognize that, even though there are forms of knowledge and expressivity with a predominant symbolic component-to think of art or religion suffices-the symbolic is a basic ingredient of every form of human knowledge and practice, as Schütz showed in his studies on the symbol, multiple realities, and everyday life. The symbol is not situated before or alongside knowledge and action, but forms the terrain in which they set their roots. By this, the intention is certainly not to deny that in many cases the symbol has been used as a screen to hide countless forms of irrationalism. This happened when the symbol was presented not as a tool of the hermeneutics of reality but simply as its negation or concealment. For example, for structuralism, the meaning of symbols substantially results from the relationship between signs and not from the relationship between signs, the world, and interpretants. In structuralism, the symbol seems to free the sign from its servitude to reality (Hawkes 1977). In an even more radical manner, Baudrillard claimed that "the symbolic is neither a concept, an agency, a category, nor a structure, but an act of exchange and a social relation which puts an end to the real, which resolves the real, and, at the same time, puts an end to the opposition between the real and the imaginary" (1993: 133). Instead, in a critical realist relational perspective the fact that knowledge is always "symbolically mediated" means that "between the subject and the object (reality) of knowledge there operate perhaps even paradoxical principles of symbolic analogy and co-relation, which are based in re and are not simple mental states or representations" (Donati 2002: 46). An affirmation that could belong to relational realism is that of Alexander (1987: 269-272), according to whom if language breaks the nexus between signifier and signified, this dissolves the relationship between individual actions and collective order.

To overcome the contrast between symbol and rationality it is necessary to recognize that "reasoning processes take symbolic inputs and deliver symbolic outputs" (Simon 1990: 5). In this sense, the symbolic is not, first of all, an annulment of the real or its dissimulation, but the depth of the real; that is, the symbolic is an essential dimension of the real, it is the notperceived in immediate objects of perception, without which we cannot gain access to the empirical reality (see Iser 1978). Symbols refer to provinces of meaning that transcend the experience of everyday life, but the task of the sociology of symbolic processes is to highlight that, thanks to symbols, these provinces are not, as Schütz had it, completely "finite" and "separate," since 
in every symbol the appresented element transcends everyday life whereas the appresenting element is part of everyday life, thus also becoming the condition enabling human communication. Despite being characterized by a rich semantic pluralism, when symbols transcend the practice of everyday life, they do indeed "leap" into other spheres to everyday life. However, they do not lose their roots (attested to by the appresenting reference) in everyday life itself, otherwise they would lose one of their essential characteristics, that is, their being public and therefore socially recognizable and sharable. It could also be said that symbols do not constitute an "autistic" reality (Wagner 1986: 6); they are not necessarily contained in an autonomous semioticlinguistic system completely separate from the reality it refers to and from the social. In a relational perspective, "the symbolic (...) can have its own rationality (symbolic rationality), which is by no means the instrumental rationality of utility, but is neither that of an irrational myth separate from its relational contents" (Donati 2008: 101). The symbolic can be situated within a certain canon of rationality only if rationality is conceived of in relational terms by overcoming the glitches that postmodern culture ran into-at the mercy on the one hand of utilitarian functionalism and on the other hand of a mythical thought based on relativism and without any more bonds with history. A wide-ranging concept of reason includes a rationality of means and resources (instrumental rationality), a rationality of value as a situated purpose (rationality aimed at the purpose), a rationality of the relationship (relational rationality), and a rationality of value as an asset in itself (symbolic rationality) (see Donati 2008: 103-114).

After having investigated the nature of the symbolic We-relation and the type of rationality involved in symbolization, the possibility finally emerges of newly examining the relationship between the symbolic Werelation and Self-reflexivity. If reason is conceived of as:

the human being's reflexive faculty, consisting of the capacity of the Self to converse with itself about itself and the world, then to expand reason is to expand this reflexive capacity (which chooses purposes, means, standards and values) through the relations that it implies with the Self and with the world through its own Self. This enables individuals to root their cultural identity in their human nature and in (natural and social) practices, while expanding outside them, into culture, and then interacting with them in the various spheres of life, where the Self becomes a Me, a We, a You (Donati 2008: 111). 
In other words, it is necessary to re-examine reflexivity as "a meaningful and consistent way for an entity to refer to itself through/with/within the relationship to the other" (Donati 2011: 193). In order not to fall into hypo-socialized or hyper-socialized conceptions of Self-reflexivity it is necessary to try to point out the immanence and at the same time excess of the reflexive Self with respect to the discourse of society and its symbols.

This enlargement of rationality, set out by relational theory, seems to be able to enter fruitfully into the debate underway in contemporary social theory on the need to draw up a social theory of the reflexive Self that combines Mead's "I-Me" model with Peirce's "I-You" model (see in particular Archer 2003; Gattamorta 2010: chap. 3; Wiley 1994). To describe the semiotic Self in the light of Peirce's view that the Self is a sign, Wiley hypothesizes that the Self is the union of three triads: the dialogic triad ("IMe-You"); the temporal triad (present-past-future) and the semiotic (signobject-interpretant). Human beings are the three triads together, including both the individual elements and the relations between them: "I-presentsign;" "Me-past-object;" "You-future-interpretant." On the semiotic level, the "I-present" functions as the sign, the "Me-past" as the object and the "You-future" as the interpretant; direct conversation between "I" and "You" is also the interaction between sign and interpretant and between present and future and involves the present Self ("I") speaking to the future Self ("You") of the past Self ("Me"). For Wiley, "human beings that are being shaped by culture have natures of their own, independently of culture. This nature or structure is the semiotic I, viewed, not as a process, but as the structure that engages in the process" (1994: 219).

The "Me" or historical phase of the Self in Mead could be compared with the "critical Self" in Peirce, understood as awareness of the individual and seat of the inner inclinations matured in the course of life and turned into habits of responding in a particular way in certain circumstances. However, the former is a socialized deposit, whereas the latter is a personalized sediment (see Archer 2003: 73). The dialogue, and in some cases the diatribe, between the "I" and the critical Self of Peirce begins when the "I" seeks to convince the critical Self, inclined to routine action, that it is worth undertaking a new course of action different from the habitual one: "When one reasons, it is that critical Self that one is trying to persuade" (Peirce 1931-1958, vol. 5, par. 421).

Peirce rejects Cartesian subjectivism and James' "absolute insulation" and argues that the mind is a theatre where "the deliberations that really and sincerely agitate our breasts always assume a dialogic form" (Peirce 
MS 318: 13d). But if "thinking always proceeds in the form of a dialogue, a dialogue between different phases of the ego" (Peirce 1931-1958, vol. 4, par. 6), then it becomes necessary to use signs and symbols that are accessible to all in the public sphere and that comprehend not only verbal but also non-verbal language. ${ }^{6}$

Correcting in part the marked externalism present in his early thought and synthesized by the statement "my language is the sum total of myself" (1931-1958, vol. 5, par. 314), Peirce considers that language and the system of semiosis are indispensable instruments for bringing the internal personal world into view and that they can be utilized in an active and innovative way: as Colapietro interprets Peirce, "language is not simply something to which I conform myself; it is something by which I transform myself" (1989: 110; see Peirce MS 290: 58-63). Peirce does not annul interiority, but rather claims that it emerges from the external world and that subjectivity is constituted through the objective means of language forming part of the public sphere. For Peirce it is the public sphere that comprehends language, the point from which human beings start in order to acquire a private sphere for themselves. Thought depends on the use of intersubjective symbols (such as visual forms, verbal and non-verbal language, etc.) also because none of us-as Pierce notes in a lapidary affirmation-is "shut up in a box of flesh and blood," we have instead an "outreaching identity" (as words have) which emerges through communication with others (1931-1958, vol. 7, par. 591).

Only from the relationship between reflexivity and interpersonal dialogue can a relative Self-autonomy emerge. If in interior dialogue subjects do not speak to society but about society, we then need to ask how and to what extent the properties and powers of social networks influence the interior dialogue. A reflexive Self is relatively autonomous when it seeks a mediation between the objective power of the social structure over action and the subjective power that we all have to make resolutions and pursue projects in light of circumstances and social relations that do not determine us completely. In particular, while investigating how subjectivity is formed and emerges in the interaction with symbols (which include not only the public linguistic medium, but also the interior verbal and non-verbal lan-

\footnotetext{
6 If Peirce underlines the importance of those indispensable symbols, such as linguistic ones, linked to a sensorial imaginary for human thought to dialogically and reflexively make its resolutions, even more radically Archer upholds that human thought emerges and is expressed through embodied practice, therefore underlining that temporally pre-verbal practice precedes verbal practice: "pre-verbal practical action is the source of basic principles of logical reasoning which are prior to and necessary for discursive socialisation" (Archer 2000: 152).
} 
guage, practical actions, and visual messages), a sociology of symbolic processes should try to avoid both subjectivism and the relationism according to which the relation has the ontological priority over the existence of consciousness. Investigating how subjectivity is formed and emerges in the interaction with symbols does not imply that symbols determine consciousness, it means that consciousness relates with itself and at the same time with something other than itself and that it can only develop through these relations.

Bibliography:

/// Alexander J.C. 1987. Twenty Lectures: Sociological Theory Since World War II, Columbia University Press.

/// Alexander J.C., Smith P. 2002. The Strong Program in Cultural Theory: Elements of a Structural Hermeneutics, [in:] Handbook of Sociological Theory, ed. J.H. Turner, Kluwer Academic, pp. 135-150.

/// Archer M.S. 2000. Being Human: The Problem of Agency, Cambridge University Press.

/// Archer M.S. 2003. Structure, Agency and the Internal Conversation, Cambridge University Press.

/// Archer M., Donati P. 2015. The Relational Subject, Cambridge University Press.

/// Baudrillard J. 1993. Symbolic Exchange and Death, Sage Publications.

/// Bourdieu P. 1991. Language and Symbolic Power, Polity Press.

/// Colapietro V.M. 1989. Peirce's Approach to the Self, State University of New York Press.

/// Donati P. 2002. Introdurione alla sociologia relazionale, $6^{\text {th }}$ ed., FrancoAngeli.

/// Donati P. 2008. Oltre il multiculturalismo. La ragione relazionale per un mondo comune, Laterza.

/// Donati P. 2009. Teoria relazionale della società: $i$ concetti di base, FrancoAngeli. 
/// Donati P. 2011. Relational Sociology: A New Paradigm for the Social Sciences, Routledge.

/// Donati P. 2015. Manifesto for a Critical Realist Relational Sociology, "International Review of Sociology", vol. 25(1), pp. 86-109.

/// Gattamorta L. 2010. La società e i suoi simboli, Carocci.

/// Habermas J. 1988. On the Logic of the Social Sciences, MIT Press.

/// Hałas E., ed. 2002a. Symbols, Power and Politics, Peter Lang.

/// Hałas E. 2002b. Symbolism and Social Phenomena: Toward the Integration of Past and Current Theoretical Approaches, "European Journal of Social Theory", vol. 5(3), pp. 351-366.

/// Hawkes T. 1977. Structuralism and Semiotics, Routledge.

/// Iser W. 1978. The Act of Reading: A Theory of Aesthetic Response, Routledge and Kegan Paul.

/// Ivana G.I. 2016. Present Contemporaries and Absent Consociates: Rethinking Schütz's "We Relation" Beyond Copresence, "Human Studies", vol. 4, pp. $513-531$.

/// Mead G.H. 1934. Mind, Self and Society: From the Standpoint of a Social Behaviourist, University of Chicago Press.

/// Peirce C.S. 1931-58. Collected Papers of Charles Sanders Peirce, 8 vols., Harvard University Press.

/// Schütz A. 1942. Scheler's Theory of Intersubjectivity and the General Thesis of the Alter Ego, "Philosophy and Phenomenological Research", vol. 2(3), pp. 323-347.

/// Schütz A. 1951. Making Music Together: A Study in Social Relationship, "Social Research", vol. 18(1), pp. 76-97.

/// Schütz A. 1956. Mozart and the Philosophers, "Social Research", vol. 23(2), pp. 219-242.

/// Schütz A. 1972. Symbol, Reality and Society, [in:] Collected Papers I: The Problem of Social Reality, Martinus Nijhoff, pp. 287-356.

/// Schütz A., Luckmann T. 1975. Die Strukturen der Lebenswelt I, Luchterhand [Eng. transl.: The Structures of the Life-World I, transl. R.M. Zaner, H.T. Engelhardt Jr., Northwestern University Press, 1973.] 
/// Simon H.A. 1990. Reason in Human Affairs, Stanford University Press.

/// Sperber D. 1975. Rethinking Symbolism, Cambridge University Press.

/// Wagner R. 1986. Symbols that Stand for Themselves, University of Chicago Press.

/// Wiley N. 1994. The Semiotic Self, Polity Press.

Archival materials:

/// Houghton Library, Harvard University: Charles S. Peirce Papers, 17871951 (MS Am 1632): MS 290, Peirce C.S. 1839-1914. Issues of Pragmaticism (CP).

/// Houghton Library, Harvard University: Charles S. Peirce Papers, 17871951 (MS Am 1632): MS 318, Peirce C.S. 1839-1914. Pragmatism (Prag).

\section{/// Abstract}

This essay considers the features constituting the symbolic We-relation to seek how the reflexive Self can generate changes to the Self, the You, and the We-relation itself. While critically dialoguing with phenomenological and pragmatist social theories, the essay investigates how subjectivity emerges in the interaction with (verbal and non-verbal) symbols and tries to avoid both subjectivism and the relationism.

Keywords:

reflexive Self, We-relation, rationality, sociology of symbolic processes

/// Lorenza Gattamorta-associate professor in sociology of cultural and communicative processes at the University of Bologna, Department of Political and Social Sciences. Some of her research was financed by: British Academy, AHRB, Accademia dei Lincei, CNR. Her publications include: Teorie del simbolo. Studio sulla sociologia fenomenologica (2005), La società e i suoi simboli (2010). She edited: „Persona” in sociologia (2008), Riflessività e sé dialogico (2008), Verso una società post-secolare? (2009), I valori hanno bisogno della religione? (2012).

E-mail: lorenza.gattamorta@unibo.it 